\title{
Effects of Acute and Chronic Exposure to Semicarbazide on the Sea Cucumber Apostichopus japonicus
}

\author{
Xiuhui Tian ${ }^{1}$, Huanjun $L^{1}{ }^{1 *}$, Xiuzhen Zhang ${ }^{1}$, Yingjiang X ${ }^{1}{ }^{1}$, Huawei Zhang ${ }^{1}$, Dianfeng Han ${ }^{1}$, \\ Huan Liu ${ }^{2}$, Bin Wang ${ }^{1}$, Yanmei Cui ${ }^{1}$, Huihui Liu ${ }^{1}$, Quanli Zhou ${ }^{1}$ and Xianghong Gong ${ }^{1 *}$ \\ ${ }^{1}$ Shandong Key Laboratory of Marine Ecological Restoration, Shandong Marine Resource and Environment Research Institute, \\ Yantai, China, ${ }^{2}$ College of Food Sciences and Technology, Shanghai Ocean University, Shanghai, China
}

OPEN ACCESS

Edited by: Yang-Guang Gu, Chinese Academy of Fishery Sciences, China

Reviewed by: Elvis Genbo Xu, University of Southern Denmark, Denmark Ahmed Esmat Abdel Moneim, Helwan University, Egypt Chenglong Ji,

Yantai Institute of Coastal Zone Research (CAS), China Xiaoyong Zhang, South China Agricultural University,

China

*Correspondence: Huanjun Li lihuanjun2020@126.com Xianghong Gong ggxxhh123@163.com

Specialty section: This article was submitted to Toxicology, Pollution and the Environment,

a section of the journal Frontiers in Environmental Science

Received: 18 March 2021 Accepted: 06 July 2021 Published: 30 August 2021

Citation:

Tian X, Li H, Zhang X, Xu Y, Zhang H, Han D, Liu H, Wang B, Cui Y, Liu H, Zhou $Q$ and Gong X (2021) Effects of Acute and Chronic Exposure to Semicarbazide on the Sea Cucumber Apostichopus japonicus.

Front. Environ. Sci. 9:682221. doi: 10.3389/fenvs.2021.682221
The effects of acute and chronic exposure to semicarbazide were carried out on the sea cucumber Apostichopus japonicus. A half-maximal lethal concentration of $3.72 \mathrm{~g} / \mathrm{L}$ of semicarbazide hydrochloride (95\% confidence interval 3.43-4.02 g/L) was deduced. At 20,4 , and $2 \%$ of the half-maximal lethal concentrations, a 28 -days exposure induced morphological alterations, oxidative stress, and acetylcholinesterase (AChE) activity in the respiratory tree, intestinal tract, and longitudinal muscle of $A$. japonicus. Exposure to $20 \%$ of the half-maximal lethal concentration resulted in lesions in the respiratory tree and disintegration in the intestinal tract. Exposure to lower concentration induced a gradual accumulation of lesions in the respiratory tree, intestinal tract, and longitudinal muscle. Levels of markers of oxidative stress and neurotransmission, including superoxide dismutase (SOD), catalase, and AChE, were increased during the initial days of exposure and then decreased. The activity of SOD, catalase, and AChE were highest in A. japonicus exposed to $4 \%$, followed by 20 and $2 \%$ of the half-maximal lethal concentration at the same time. At the later stages of the 28-days exposure, marker levels were decreased and close to levels in the control groups. Non-targeted metabolomics indicated that significantly different metabolites were screened out, 28 in the positive ion mode and 38 in the negative ion mode, impairments in neurological function, osmotic pressure regulation, energy metabolism, and protein digestion and absorption following exposure of $A$. japonicus to semicarbazide. KEGG pathway enrichment showed that the exposure affected pathways related to $A B C$ transporters, central carbon metabolism in cancer, protein digestion and absorption, aminoacyl-tRNA biosynthesis, and biosynthesis of unsaturated fatty acids.

Keywords: semicarbazide, oxidative stress, AChE activity, metabolomics, significantly different metabolites

\section{INTRODUCTION}

Semicarbazide, also termed carbamoylhydrazine, was a photochromic dye used in thermal recording paper and an intermediate in the synthesis of prednisone and adrenobazone (Nardelli et al., 1965; Raja et al., 2017; Tarek et al., 1986). Semicarbazide was also a minor product of the decomposition of azodicarbonamide at high temperatures (Becalski et al., 2004; Becalski et al., 2006). More importantly, semicarbazide was a marker residue of nitrofurazone as a veterinary drug (Communities, 1993; Communities, 1995; Register, 2002). A recommended maximum of 
semicarbazide residue level of $1 \mu \mathrm{g} / \mathrm{kg}$ in aquatic products including sea cucumbers had been established in China, the European Union, and the US (Register, 2002; Communities, 2003). Semicarbazide was toxic weakly and carcinogenic potentially and could be harmful at high concentrations in food (EFSA, 2003a; EFSA, 2003b; EFSA, 2003c; Hirakawa et al., 2003; Authority 2005; Takahashi et al., 2014; Wang et al., 2016; Yu et al., 2016).

Semicarbazide could enter the oceans through various routes and be considered an emerging marine pollutant (Gao et al., 2014; Tian et al., 2017; Tian et al., 2016). Semicarbazide can lower the concentration of endogenous 17 $\beta$-estradiol, inhibiting the maturation of the ovary in female zebrafish eventually ( $\mathrm{Yu}$ et al., 2016). In addition, semicarbazide can alter the testicular morphology in male zebrafish and lower the testicular somatic index, reducing ability of reproductive regulatory ultimately (Yu et al., 2017). Semicarbazide interfered with the transmission of nerve signals and led to relevant behaviors abnormal by antagonizing NMDAR and inhibiting glutamic acid decarboxylase (GAD) (Santos et al., 2008). Semicarbazide has been evidenced to be an inhibitor of mediated effect between GAD and GABA, which has been verified in the reproductive system of the male zebrafish, causing disorder through GABA in males (Yu et al., 2017). The Shandong Peninsula Blue Economic Zone, subjected to a national development strategy in China, was an area where the pollutants could affect the marine organisms and the humans negatively who consumed them (Fleming et al., 2006; Partelow et al., 2015).

Apostichopus japonicus, cultured in the Yellow Sea and the Bohai Sea mainly, was considered to yield the highest nutritional value, being high in protein and low in fat (Xia et al., 2012). The culture of $A$. japonicus was a large industry and had been expanded from Shandong and Liaoning to several southern provinces (Dong 2007; Liu et al., 2012). Developments of science and technology had promoted aquaculture techniques, but food and water quality and disease control posed challenges that restricted the economic benefits of A. japonicus. Recently, the use of prohibited drugs had been controlled to a great extent, but emerging contaminants in the ocean remained a concern in the culture of $A$. japonicus.

Semicarbazide has been detected in A. japonicus and the residues, which had caused great economic losses. A. japonicus, the most famous in the Yellow Sea and Bohai Sea, was taken as the object in this research (Zhao et al., 2016). The acute and chronic toxicity of $A$. japonicus under semicarbazide stress was studied systematically utilizing biochemistry, histochemistry and modern metabolomics technology. The half-maximal lethal concentration $\left(\mathrm{LC}_{50}\right)$ of semicarbazide to A. japonicus was derived. Respiratory tree has the functions of excretion and respiration, completing the gas exchange between body cavity fluid and seawater. The intestinal tract was the main feeding tissue of $A$. japonicus. Muscle tissue was the main edible tissue. Therefore, respiratory tree, intestinal tract, and muscle tissue were selected as the main objectives. The chronic effects on the respiratory tree, intestinal tract, and muscle tissue were conducted. The tissue-specific oxidative effects were discussed using the antioxidant enzymes superoxide dismutase (SOD) and catalase. Also, the activity of AChE was determined to assess the biological neurotoxicity. The non-targeted metabolomics were supplemented to deduce the significantly different metabolites and pathways involved in toxicity. The research could provide a reference for the residual mechanism and pollution control, and data support for the health and ecological risk assessment of semicarbazide in A. japonicus.

\section{MATERIALS AND METHODS}

\section{Chemicals and Materials}

A. japonicus was bred for the $\mathrm{LC}_{50}$ test artificially by Penglai Anyuan Aquatic Products Co., Ltd. (Shandong Province, China). Average body length was $12.6 \pm 0.70 \mathrm{~cm}$ and body weight $25.0 \pm$ $3.10 \mathrm{~g}$, fasted during the whole experiment. The following chemicals were used in morphological alterations: Semicarbazide existed in the form of hydrochloride, and was obtained from Dr. Ehrenstorfer, with purity more than $98 \%$. Bouin's solution was mixed using $75.0 \mathrm{ml}$ of the saturated picric acid solution, $25.0 \mathrm{ml}$ of formaldehyde solution (40\%), and $5.00 \mathrm{ml}$ of glacial acetic acid. Picric acid was purchased from Shantou Xilong Chemical Factory (Guangdong, China). Paraffin sections were purchased from Shanghai Hualing Rehabilitation Appliance Factory (Shanghai, China). Anhydrous ethanol, xylene, formaldehyde, and glacial acetic acid were of analytical grade and purchased from Guoyao Group Chemical Reagent Co., Ltd. (Shanghai, China).

\section{Instruments}

The instruments used in morphological alterations were an automatic tissue dehydrator (TP1020, Leica, Wetzlar, Germany), a light microscope (DM500, Leica, Germany), a paraffin embedding machine (Histocentre 2, Shandon, United Kingdom), a rotary slicer (type 202, Shanghai No. 4 Medical Appliance Factory, Shanghai, China), an autostainer (ST5010, Leica, Germany), and a film spreader (ZPJ-1, Tianjin Tianli Aviation Mechanical \& Electrical Co., Ltd., Tianjin, China).

The following instruments were used in oxidative stress and AChE measurements: clean bench (SW-CJ-2FD, Shanghai Sujing Industry Co., Ltd., Shanghai, China); desktop centrifuge (Sorvall BioFuge Stratos, Thermo Fisher Scientific, United States); electronic balance (PL4002, Mettler Toledo, Switzerland); constant temperature water bath (CHB-100, Hangzhou Borges Technology Co., Ltd., Hangzhou, China); liquid nitrogen biological vessel (YDS-10, Leshan East Asia Mechanical \& Electrical Industry Co., Ltd., Leshan, China); pipetter (ADJ, Eppendorf, Hamburg, Germany); microplate reader (Bio-Rad Laboratories, Hercules, CA, United States); ultraviolet spectrophotometer (TU-1810, Beijing Puxin General Instruments Co., Ltd., Beijing, China); icemaker (FM40, Shanghai Yanzheng Experimental Instrument Co., Ltd., Shanghai, China); portable high-speed dispersion leveler (PB100, Suzhou Huamei Chen Instruments Co., Ltd., Suzhou, China). 


\section{METHODS}

\section{Acute Toxicity}

A. japonicus exhibiting good activity were selected for temporary culture in a laboratory tank for three days and then allocated to water basins containing $25.0 \mathrm{~L}$ seawater at a water temperature of $16.0 \pm 1.0^{\circ} \mathrm{C}$ and $30 \pm 1.0 \%$ salinity. The seawater was oxygenated continuously, and the dissolved oxygen was $6.5-7.0 \mathrm{mg} \mathrm{L}^{-1}$ in the experiment. The $\mathrm{pH}$ was $7.0-7.5$, and the seawater met the standard of the fishery water quality (GB11607-89 Water quality standard for fisheries). During the experiment, seawater was changed by $50 \%$ every day, and semicarbazide was supplemented to the original concentration, which was determined as the reference (Tian et al., 2016).

In the preliminary experiment, the exposure concentrations selected were $0.05,0.50,1.00,2.00$, and $5.00 \mathrm{~g} / \mathrm{L}(10-15$ in each basin, two replications) of semicarbazide hydrochloride, and the animals were observed for $96 \mathrm{~h}$. No death occurred in $A$. japonicus exposed to 0.05 or $0.50 \mathrm{~g} / \mathrm{L}$, and $A$. japonicus exposed to $5.00 \mathrm{~g} / \mathrm{L}$ semicarbazide died. Therefore, five concentrations were selected between the highest and the lowest lethal concentration observed in the range-finding experiment $(2.50,3.00,3.50,4.00$, and $4.50 \mathrm{~g} / \mathrm{L})$. A. japonicus $40-50$ in each basin (25.0 L seawater) were exposed to these concentrations, three replicates for each concentration and one for control.

\section{Morphological Alterations}

A. japonicus used were also bred artificially by Penglai Anyuan Fishery Co., Ltd. and of the same measurements. The animals were acclimated in a laboratory culture tank $(40 \mathrm{~L})$ for three days, and the experiments were then conducted at a water temperature of $16.0 \pm 1.0^{\circ} \mathrm{C}$ and $30 \pm 1.0 \%$ salinity. One-half of the water was changed daily, and the tank was oxygenated continuously. The animals were fasted $24 \mathrm{~h}$ before the experiment, then treated with semicarbazide at a high $\left(20 \%\right.$ of the $\left.\mathrm{LC}_{50}\right)$, medium $(4 \%$ of the $\mathrm{LC}_{50}$ ), or low ( $2 \%$ of the $\mathrm{LC}_{50}$ ) concentration. The 3-5 A. japonicus were sampled on the days of $1,2,3,4,5,6,7,10$, 14,21 , and 28 of the exposure.

The tissues including respiratory tree, intestinal tract, and muscle of 3-5 A. japonicus were fixed in 10 times or more volume of Bouin's solution $24 \mathrm{~h}$ directly and integrally and then transferred to $70 \%$ alcohol for storage. The fixed tissues were dehydrated, made transparent, and immersed in wax, embedded in paraffin, cut into segments manually after trimming, baked at $60^{\circ} \mathrm{C}$, stained with hematoxylin-eosin, sealed with neutral gum, then observed under a light microscope and photographed (Rajeshkumar et al., 2017).

\section{Oxidative Stress Measurements}

A. japonicus were exposed as the morphological alterations test meanwhile. 3-5 A. japonicus samples for enzyme activity measurements were placed in $2.0 \mathrm{ml}$ cryovials, including respiratory tree, intestinal tract, and muscle, stored in the liquid nitrogen immediately, and then frozen at $-80^{\circ} \mathrm{C}$. Tissue aliquots $(0.20 \mathrm{~g})$ were added to $0.75 \%$ normal saline at a ratio of 1 : 4 (longitudinal muscle) and 1:9 (respiratory tree and intestinal tract). The tissue was homogenized in an ice bath with a portable high-speed disperser. The homogenate tissue fluid was then centrifuged for $10 \mathrm{~min}\left(4^{\circ} \mathrm{C}, 12,000 \mathrm{rpm}\right)$. The supernatant was used to measure SOD and catalase with a kit from Nanjing Jiancheng Bioengineering Institute (Nanjing, China).

\section{AChE Activity}

Reagents, equipment, and experimental were identical to those used for the oxidative stress. A. japonicus were exposed as the morphological alterations test meanwhile, including respiratory tree, intestinal tract, and muscle. The supernatant was collected to determine AChE activity with a kit from Nanjing Jiancheng Bioengineering Institute (Nanjing, China) (Zhao et al., 2014).

\section{Metabolomics}

Breeding conditions of $A$. japonicus were identical to those used in the oxidative stress test. The vitality was observed daily and the died were discarded immediately. A. japonicus were divided into twelve tanks randomly (six control groups and six semicarbazideexposure groups), each containing 10-16 A. japonicus and $25 \mathrm{~L}$ of seawater. A. japonicus were treated with $3.72 \mathrm{~g} / \mathrm{L}$ semicarbazides for $72 \mathrm{~h}$. After $72 \mathrm{~h}$ exposure, the intestinal tract was taken and placed in the $1.5 \mathrm{ml}$ cryotubes. Each cryotube sample contained the intestinal tract of eight individuals. After collecting $8 \mathrm{~A}$. japonicus for each treatment, the samples were snap-frozen and stored at $-80^{\circ} \mathrm{C}$ for metabolomics analysis. The hydrophilic interaction liquid chromatography-ultra highperformance liquid chromatography-quadrupole time-of-flight mass spectrometry (AB SCIEX Triple TOF 5600+) was used to analyze the changes in the metabolic profiles of $A$. japonicus exposed to semicarbazide in Shanghai Applied Protein Technology, Ltd. (Shanghai, China).

Chromatographic separation of the metabolites was performed on an ACQUITY BEH C18 column (100 mm $2.1 \mathrm{~mm}$ i. d., $1.7 \mu \mathrm{m}$; Waters, Milford, United States). The mobile phases consisted of $0.1 \%$ formic acid in water (solvent A) and $0.1 \%$ formic acid in acetonitrile: isopropanol $(1: 1, \mathrm{v} / \mathrm{v})$ (solvent $\mathrm{B}$ ). The solvent gradient changed according to the following conditions: from 0 to $3 \mathrm{~min}, 95 \%$ (A) to $80 \%$ (A); from 3 to $9 \mathrm{~min}, 80 \%$ (A) to $5 \%$ (A); from 9 to $13 \mathrm{~min}, 5 \%$ (A) to $5 \%$ (A); from 13 to $13.1 \mathrm{~min}, 5 \%$ (A) to $95 \%$ (A), from 13.1 to $16 \mathrm{~min}, 95 \%$ (A) to $95 \%$ (A) for equilibrating the systems. The injection volume was $2 \mu \mathrm{l}$ and the flow rate was set to $0.4 \mathrm{ml} / \mathrm{min}$. The column temperature was maintained at $40^{\circ} \mathrm{C}$. During the period of analysis, all these samples were stored at $4^{\circ} \mathrm{C}$.

The data of mass spectrometric was collected using a Thermo UHPLC-Q Exactive Mass Spectrometer equipped with an electrospray ionization (ESI) source operating in positive and negative ion mode. The optimal conditions were set as followed: Aus gas heater temperature, $400^{\circ} \mathrm{C}$; Sheath gas flow rate $40 \mathrm{psi}$; Aus gas flow rate $30 \mathrm{psi}$; ionspray voltage floating (ISVF), $-2800 \mathrm{~V}$ in negative mode and $3500 \mathrm{~V}$ in positive mode, respectively; Normalized collision energy, 20-40-60 V rolling for MS/MS. Data acquisition was performed on the Data Dependent Acquisition (DDA) mode. The detection was carried out over a mass range of $70-1,050 \mathrm{~m} / \mathrm{z}$. 
TABLE 1 | Mortality of each experimental group of semicarbazide in A. japonicas.

\begin{tabular}{|c|c|c|c|c|c|c|}
\hline Concentration & 0 & $2.50 \mathrm{~g} / \mathrm{L}$ & $3.00 \mathrm{~g} / \mathrm{L}$ & $3.50 \mathrm{~g} / \mathrm{L}$ & $4.00 \mathrm{~g} / \mathrm{L}$ & $4.50 \mathrm{~g} / \mathrm{L}$ \\
\hline Mortality of 24 h (\%) & 0 & 0 & 0 & 0 & 0 & 0 \\
\hline Mortality of 48 h (\%) & 0 & 0 & 0 & 0 & 0 & 5 \\
\hline Mortality of 72 h (\%) & 0 & 0 & 0 & 5 & 10 & 20 \\
\hline Mortality of 96 h (\%) & 0 & 5 & 20 & 30 & 50 & 85 \\
\hline
\end{tabular}

TABLE 2 | Probability and confidence limit of semicarbazide in A. japonicas.

\begin{tabular}{|c|c|c|c|c|c|c|}
\hline \multirow[t]{2}{*}{ Probability } & \multicolumn{3}{|c|}{$95 \%$ confidence limit of VAR00001 } & \multicolumn{3}{|c|}{$95 \%$ confidence limit of LogVAR00001a } \\
\hline & Possibility & Lower limit & Upper limit & Possibility & Lower limit & Upper limit \\
\hline 0.100 & 2.866 & 2.369 & 3.158 & 0.457 & 0.374 & 0.499 \\
\hline 0.200 & 3.135 & 2.718 & 3.399 & 0.496 & 0.434 & 0.531 \\
\hline 0.300 & 3.344 & 2.988 & 3.601 & 0.524 & 0.475 & 0.556 \\
\hline 0.400 & 3.534 & 3.223 & 3.802 & 0.548 & 0.508 & 0.580 \\
\hline 0.500 & 3.721 & 3.437 & 4.025 & 0.570 & 0.536 & 0.604 \\
\hline 0.600 & 3.918 & 3.641 & 4.291 & 0.593 & 0.561 & 0.632 \\
\hline 0.700 & 4.141 & 3.847 & 4.626 & 0.617 & 0.585 & 0.665 \\
\hline 0.800 & 4.417 & 4.076 & 5.084 & 0.645 & 0.610 & 0.706 \\
\hline 0.900 & 4.832 & 4.388 & 5.832 & 0.684 & 0.642 & 0.765 \\
\hline
\end{tabular}

${ }^{a}$ Meant base 10.

TABLE 3 | 28 significantly different metabolites in positive ion mode.

\begin{tabular}{|c|c|c|c|c|c|c|}
\hline Name & Adduct & Description & VIP & Fold change & p-value & $\mathrm{m} / \mathbf{z}$ \\
\hline М232Т396 & $(\mathrm{M}-\mathrm{H}+2 \mathrm{Na})+$ & N1-Acetylspermidine & 1.01928 & 12.7710183 & 3.3017E-09 & 232.140301 \\
\hline M251T217 & $(\mathrm{M}+\mathrm{H}-\mathrm{H} 2 \mathrm{O})+$ & Inosine & 1.39082 & 3.97806297 & $1.4554 \mathrm{E}-08$ & 251.077278 \\
\hline M162T740 & $(\mathrm{M}+\mathrm{H})+$ & DL-2-Aminoadipic acid & 2.96321 & 2.49337877 & 1.717E-08 & 162.076112 \\
\hline М300Т216 & $(\mathrm{M}+\mathrm{H}-\mathrm{H} 2 \mathrm{O})+$ & Phytosphingosine & 2.69746 & 4.6019815 & 1.4888E-07 & 300.289958 \\
\hline M298T151 & $(\mathrm{M}+\mathrm{H})+$ & S-Methyl-5'-thioadenosine & 5.93823 & 3.65223278 & 3.5675E-07 & 298.09718 \\
\hline M250T164 & $(\mathrm{M}+\mathrm{H}-\mathrm{H} 2 \mathrm{O})+$ & Adenosine & 2.52326 & 3.13603953 & 8.1926E-06 & 250.093383 \\
\hline M182T530 & $(\mathrm{M}+\mathrm{H})+$ & L-Tyrosine & 2.10544 & 2.20392993 & 2.3909E-05 & 182.080596 \\
\hline M136T531 & $(\mathrm{M}+\mathrm{H}-\mathrm{H} 2 \mathrm{O})+$ & Dopamine & 1.00825 & 1.87267787 & 3.1123E-05 & 136.075719 \\
\hline M230T578 & $(\mathrm{M}+\mathrm{H})+$ & Ergothioneine & 3.96736 & 1.37556952 & 3.2853E-05 & 230.095659 \\
\hline M428T262 & $(\mathrm{M}+\mathrm{H})+$ & Stearoylcarnitine & 1.27828 & 2.56418612 & 4.1936E-05 & 428.373333 \\
\hline M152T387 & $(\mathrm{M}+\mathrm{H})+$ & 2-Hydroxyadenine & 1.66547 & 1.77128232 & 0.0002056 & 152.056457 \\
\hline M130T717 & $(\mathrm{M}+\mathrm{H})+$ & L-Pyroglutamic acid & 3.11644 & 0.72000643 & 0.00034202 & 130.049898 \\
\hline M148T717 & $(\mathrm{M}+\mathrm{H})+$ & L-Glutamate & 4.85673 & 0.72669476 & 0.0007822 & 148.06071 \\
\hline M379T40 & $(\mathrm{M}+\mathrm{H}-\mathrm{H} 2 \mathrm{O})+$ & Vitamin D2 (Ergocalciferol) & 1.27022 & 1.60515431 & 0.00133458 & 379.335837 \\
\hline M362T68 & $(\mathrm{M}+\mathrm{CH} 3 \mathrm{CN}+\mathrm{H})+$ & 20-Hydroxyarachidonic acid & 1.02978 & 1.40183466 & 0.0017793 & 362.269118 \\
\hline M137T306 & $(\mathrm{M}+\mathrm{H})+$ & Hypoxanthine & 3.6328 & 1.48724236 & 0.00193461 & 137.045662 \\
\hline M296T172 & $(\mathrm{M}+\mathrm{NH} 4)_{+}$ & alpha-Linolenic acid & 1.78975 & 2.20457139 & 0.00207822 & 296.25851 \\
\hline М360Т300 & $(\mathrm{M}+\mathrm{CH} 3 \mathrm{COO}+2 \mathrm{H})+$ & Sphingosine & 1.18364 & 1.79891478 & 0.00236277 & 360.310948 \\
\hline M102T717 & $(\mathrm{M}+\mathrm{H})+$ & 1-Aminocyclopropanecarboxylic acid & 1.00022 & 0.74619188 & 0.00243702 & 102.05549 \\
\hline M317T77 & $(\mathrm{M}+\mathrm{H})+$ & 15-Deoxy-delta-12,14-PGJ2 & 2.14926 & 0.49927162 & 0.00285459 & 317.211158 \\
\hline М869T82 & $(\mathrm{M}+\mathrm{CH} 3 \mathrm{CN}+\mathrm{H})+$ & PC(20:5 (5Z,8Z,11Z,14Z,17Z)/20:5 (5Z,8Z,11Z,14Z,17Z)) & 1.72318 & 0.71867544 & 0.00287811 & 868.584335 \\
\hline M400T272 & $(\mathrm{M}+\mathrm{H})+$ & L-Palmitoylcarnitine & 1.2338 & 2.04901335 & 0.00399173 & 400.341982 \\
\hline M104T416 & $M+$ & Choline & 2.87144 & 1.32470479 & 0.006406 & 104.10775 \\
\hline M146T305_2 & $(\mathrm{M}+\mathrm{H})+$ & Acetylcholine & 2.02104 & 1.43262909 & 0.02043245 & 146.117305 \\
\hline M345T77_1 & $(\mathrm{M}+\mathrm{CH} 3 \mathrm{COO}+2 \mathrm{H})+$ & Retinene & 1.10611 & 0.58791733 & 0.022496 & 345.242703 \\
\hline M138T497 & $(\mathrm{M}+\mathrm{H})+$ & Anthranilic acid (vitamin L1) & 1.49736 & 1.48196975 & 0.031229 & 138.054753 \\
\hline M126T517_2 & $(\mathrm{M}+\mathrm{H})+$ & Taurine & 1.01064 & 1.10141916 & 0.03214484 & 126.022213 \\
\hline M118T467_2 & $(\mathrm{M}+\mathrm{H})+$ & Betaine & 4.48189 & 1.08781972 & 0.04487168 & 118.086611 \\
\hline
\end{tabular}

\section{RESULTS AND DISCUSSION}

\section{Acute Toxicity}

During the preliminary experiment, the activity did not differ between the control group and those exposed to 0.050 or $0.50 \mathrm{~g} / \mathrm{L}$ semicarbazide. A. japonicus were attached to the basin walls, elongated, with sharp thorns, and were brown or green-brown. $A$. japonicus exposed to 1.00 or $2.00 \mathrm{~g} / \mathrm{L}$ semicarbazide detached and fell to the bottom of the basin, twisted and rolled, and their bodies and mouth tentacles were stretched fully, displaying restlessness. 
TABLE 4 | 38 significantly different metabolites in negative ion mode.

\begin{tabular}{|c|c|c|c|c|c|c|}
\hline Name & Adduct & Description & VIP & Fold change & p-value & $m / z$ \\
\hline M249T217 & $(\mathrm{M}-\mathrm{H} 2 \mathrm{O}-\mathrm{H})-$ & Inosine & 2.51705 & 5.45226372 & 7.7597E-10 & 249.062838 \\
\hline M117T703_2 & $(\mathrm{M}-\mathrm{H})-$ & Succinate & 1.71706 & 0.58899633 & 2.687E-09 & 117.021375 \\
\hline M281T245 & $(\mathrm{M}-\mathrm{H})-$ & 2'-O-methylinosine & 1.47976 & 5.95246379 & 5.3357E-09 & 281.088415 \\
\hline M142T242 & $(\mathrm{M}+\mathrm{NH} 4-2 \mathrm{H})-$ & 5-Amino-4-carbamoylimidazole (AICA) & 1.27833 & 14.7896583 & 9.1231E-08 & 142.074195 \\
\hline M160T741_2 & $(\mathrm{M}-\mathrm{H})-$ & DL-2-Aminoadipic acid & 3.48768 & 2.80165371 & 1.416E-07 & 160.063 \\
\hline M227T191_1 & $(\mathrm{M}-\mathrm{H})-$ & $2^{\prime}$-Deoxyuridine & 6.29324 & 3.18314261 & 1.1934E-06 & 227.067319 \\
\hline M356T172 & $(\mathrm{M}+\mathrm{CH} 3 \mathrm{COO})-$ & S-Methyl-5'-thioadenosine & 1.13177 & 3.78944029 & 2.4995E-06 & 356.101978 \\
\hline M181T525 & $(\mathrm{M}-\mathrm{H})-$ & D-Sorbitol & 1.32142 & 2.48665633 & $6.3481 E-06$ & 181.071963 \\
\hline M118T649 & $(\mathrm{M}-\mathrm{H})-$ & L-Threonine & 1.26408 & 1.71972714 & $6.8628 \mathrm{E}-06$ & 118.052574 \\
\hline M255T187 & $(\mathrm{M}-\mathrm{H})-$ & Palmitic acid & 3.25695 & 1.86628554 & 1.7208E-05 & 255.232501 \\
\hline M125T112 & $(\mathrm{M}-\mathrm{H})-$ & Thymine & 2.66659 & 3.21895132 & 4.1677E-05 & 125.036789 \\
\hline M130T525 & $(\mathrm{M}-\mathrm{H})-$ & L-Leucine & 1.12331 & 1.59188919 & 5.6428E-05 & 130.088575 \\
\hline M116T529 & $(\mathrm{M}-\mathrm{H})-$ & L-Valine & 2.06723 & 1.80198056 & 5.6964E-05 & 116.073533 \\
\hline M180T532 & $(\mathrm{M}-\mathrm{H})-$ & L-Tyrosine & 2.516 & 1.98519179 & 6.8531E-05 & 180.067428 \\
\hline M283T186 & $(\mathrm{M}-\mathrm{H})-$ & Stearic acid & 2.6075 & 1.76259253 & 6.8581E-05 & 283.263506 \\
\hline M383T717 & $(\mathrm{M}-\mathrm{H})-$ & S-Adenosyl-L-homocysteine & 1.7784 & 3.89404321 & 7.6736E-05 & 383.112385 \\
\hline M253T71 & $(\mathrm{M}-\mathrm{H})-$ & cis-9-Palmitoleic acid & 5.72216 & 2.30584534 & 8.607E-05 & 253.217245 \\
\hline M225T73 & $(\mathrm{M}-\mathrm{H})-$ & Myristoleic acid & 1.87112 & 4.3993026 & 8.9227E-05 & 225.185417 \\
\hline M111T143 & $(\mathrm{M}-\mathrm{H})-$ & Uracil & 4.24478 & 3.08444533 & 9.2286E-05 & 111.021879 \\
\hline M251T305 & $(\mathrm{M}-\mathrm{H})-$ & Deoxyinosine & 6.34626 & 1.67085611 & 9.485E-05 & 251.078711 \\
\hline M303T67_4 & $(\mathrm{M}-\mathrm{H})-$ & Arachidonic Acid (peroxide free) & 6.33937 & 1.26356942 & 0.00016879 & 303.23272 \\
\hline M135T286 & $(\mathrm{M}-\mathrm{H})-$ & Hypoxanthine & 2.49548 & 1.3681982 & 0.00023883 & 135.032583 \\
\hline M146T717 & $(\mathrm{M}-\mathrm{H})-$ & L-Glutamate & 6.43157 & 0.78158733 & 0.00051179 & 146.047893 \\
\hline M132T738 & $(\mathrm{M}-\mathrm{H})-$ & L-Aspartate & 1.56801 & 1.72739918 & 0.0005719 & 132.031946 \\
\hline M351T60 & $(\mathrm{M}-\mathrm{H})-$ & PGF3a & 1.70823 & 3.31604327 & 0.00076911 & 351.219725 \\
\hline M102T718 & $(\mathrm{M}-\mathrm{H})-$ & (S)-2-aminobutyric acid & 1.59012 & 0.74131217 & 0.00081883 & 102.058476 \\
\hline M257T240 & $(\mathrm{M}-\mathrm{H})-$ & Ribothymidine & 1.82982 & 5.01906923 & 0.00094634 & 257.0777 \\
\hline M130T455 & $(\mathrm{M}-\mathrm{H})-$ & L-Isoleucine & 2.99423 & 1.93451653 & 0.00129241 & 130.08907 \\
\hline M281T69_2 & $(\mathrm{M}-\mathrm{H})-$ & Oleic acid & 2.00905 & 1.2846784 & 0.00192897 & 281.247954 \\
\hline M119T190 & $(\mathrm{M}-\mathrm{H})-$ & Purine & 1.43357 & 2.59462046 & 0.00345782 & 119.037567 \\
\hline M138T464_3 & $(\mathrm{M}-\mathrm{H})-$ & 3-Aminopropanesulphonic Acid & 1.82068 & 1.45110728 & 0.00357767 & 138.024839 \\
\hline M241T72_2 & $(\mathrm{M}-\mathrm{H})-$ & Pentadecanoic Acid & 2.52429 & 1.51698755 & 0.00373982 & 241.217157 \\
\hline M411T73 & $(\mathrm{M}-\mathrm{H})-$ & Grayanotoxin I & 5.43935 & 1.92720144 & 0.00519505 & 411.240193 \\
\hline M243T271_1 & $(\mathrm{M}-\mathrm{H})-$ & Uridine & 2.37294 & 1.3285263 & 0.00759854 & 243.062295 \\
\hline M199T74 & $(\mathrm{M}-\mathrm{H})-$ & Dodecanoic acid & 1.3691 & 0.76504364 & 0.01634559 & 199.170477 \\
\hline M157T77 & $(\mathrm{M}-\mathrm{H})-$ & Pelargonic acid & 1.273 & 0.82934955 & 0.01725693 & 157.124169 \\
\hline M124T517_2 & $(\mathrm{M}-\mathrm{H})-$ & Taurine & 2.28211 & 1.08598318 & 0.02269878 & 124.009864 \\
\hline M367T105 & $(\mathrm{M}-\mathrm{H})-$ & Perindopril & 3.82131 & 1.5961151 & 0.0389509 & 367.214706 \\
\hline
\end{tabular}

A. japonicus exposed to $5.00 \mathrm{~g} / \mathrm{L}$ semicarbazide curled up into a ball, the flesh became blunt, the internal organs expelled, and the skin festered until death. The mortality between the highest and the lowest lethal concentration observed in the range-finding experiment was $5,20,30,50$, and $85 \%$ in $2.50,3.00,3.50,4.00$, and $4.50 \mathrm{~g} / \mathrm{L}$ of semicarbazide hydrochloride in $96 \mathrm{~h}$, as shown in Table 1.

Table 2 listed the probability and confidence limit of semicarbazide in A. japonicas. The $\mathrm{LC}_{50}$ were based on the probability unit method and the characteristics of the qualitative reaction (Finney 1972; Abou-Setta et al., 1986). A linear correlation was not established between semicarbazide concentration and mortality. However, a specific linear relationship between the logarithmic value of semicarbazide concentration and mortality was observed. The calculated 96-h $\mathrm{LC}_{50}$ of semicarbazide hydrochloride was $3.72 \mathrm{~g} / \mathrm{L} \quad(95 \%$ confidence interval $3.44-4.02 \mathrm{~g} / \mathrm{L}$ ). The linear regression equation of the logarithm of concentration to probability unit was $y=0.264 x+0.438$ (correlation coefficient $r$ 0.9965).
According to the guidelines (HJ/T154-2004 The guidelines for the hazard evaluation of new chemical substances), the ecotoxicological hazards of the chemicals were classified into four levels according to $\mathrm{LC}_{50}$, extremely high toxicity if $\mathrm{LC}_{50}$ $<1 \mathrm{mg} / \mathrm{L}$, high toxicity if $\mathrm{LC}_{50}$ within the range of $1-10 \mathrm{mg} / \mathrm{L}$, toxic if $\mathrm{LC}_{50}$ within the range of $10-100 \mathrm{mg} / \mathrm{L}$ and low toxicity if $\mathrm{LC}_{50}>100 \mathrm{mg} / \mathrm{L}$. The $\mathrm{LC}_{50}$ of semicarbazide was $26.29 \mathrm{mg} / \mathrm{L}$ in $96 \mathrm{~h}$, which was a toxic substance to zebrafish according to $\mathrm{HJ} /$ T154-2004 (Yu et al., 2017).

According to the specification for chemical safety technical of Sigma company, semicarbazide was classified as the acute toxicity in the global unified classification and labeling system. The $\mathrm{LC}_{50}$ of once oral administration to rats was $123 \mathrm{mg} / \mathrm{kg}$, which was moderately toxic $\left(\mathrm{LC}_{50}\right.$ of once oral administration was $101-1000 \mathrm{mg} / \mathrm{L}$ for moderately toxic substances). However, according to the $\mathrm{LC}_{50}$ value of semicarbazide in A. japonicus in this research, semicarbazide belonged to low toxicity, which might be related to being a lower animal of $A$. japonicus, needing further research. 


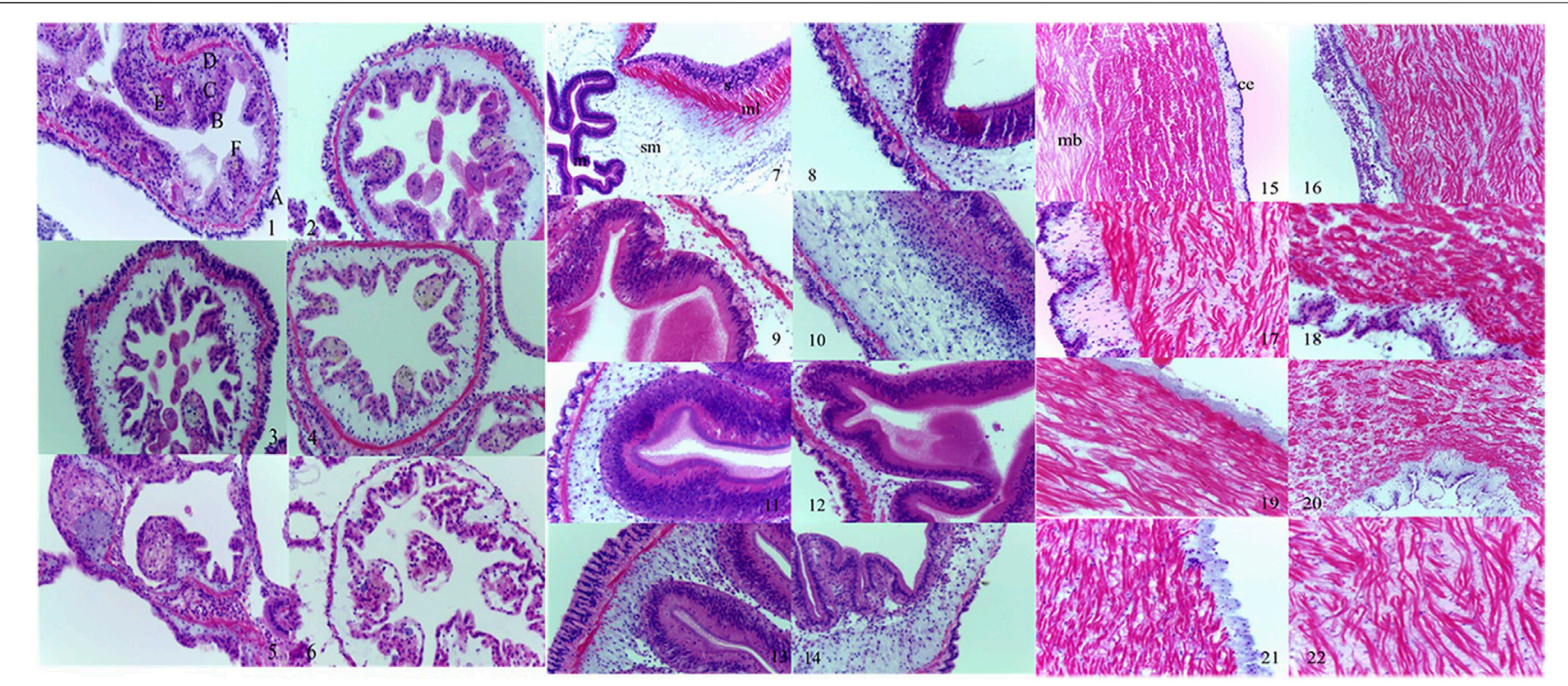

FIGURE 1 | Morphological alterations of the respiratory tree, intestinal tract, and longitudinal muscle of $A$. japonicus induced by semicarbazide. Note: 1 . control group, $\times 400 ; 2$. 20\% LC 50 group 4 days, $\times 400 ; 3.4 \%$ LC $_{50}$ group 10 days, $\times 400 ; 4.4 \% L_{50}$ group 28 days, $\times 400 ; 5.2 \%$ LC 50 group 14 days, $\times 400 ; 6.20 \%$ LC 50 group 14 days, $\times 400$; (A: upper cavity; B: endothelial cells; C: blood cavity; D: muscular layer; E: cell secretions; F: central cavity for respiratory tree); 7 . control group, $\times 400 ; 8.20 \% L_{50}$ group 2 days, $\times 400 ; 9.20 \% L_{50}$ group 14 days, $\times 400 ; 10.4 \% L_{50}$ group 6 days, $\times 400 ; 11.4 \%$ LC 50 group 14 days, $\times 400 ; 12.2 \%$ LC 50 group 6 days, $\times 400 ; 13.2 \% L_{50}$ group 7 days, $\times 400 ; 14.2 \% L_{50}$ group 14 days, $\times 400$; (s: serosa layer; ml: muscular layer; sm: the inner connective tissue layer or the submucosa; m: intestinal lumen epithelium or mucosal layer for intestinal tract); 15 . control group, $\times 200 ; 16.20 \%$ LC 50 group 5 days, $\times 200 ; 17.20 \%$ LC 50 group 7 days, $\times 200 ; 18.20 \%$ LC $_{50}$ group 14 days, $\times 200 ; 19.20 \%$ LC $_{50}$ group 28 days, $\times 200 ; 20.4 \%$ LC 50 group 5 days, $\times 200 ; 21.2 \%$ LC 50 group 7 days, $\times 400 ; 22.2 \%$ LC 50 group 14 days, $\times 400$; (ce: coelomic epithelium; mb: muscle bundle for longitudinal muscle).

\section{Morphological Alterations}

Figure 1, 1-6 showed the damage sustained by the A. japonicus respiratory tree following exposure to semicarbazide. The respiratory tree was dendritic and floated in the body cavity. The left branch was thicker relatively, extending to the vicinity of the pharynx and interweaving with the reticular structure of the dorsal blood sinus of the ascending small intestinal tract. The root was located at the upper end of the drain cavity. The terminal end of the fine branches was a small sac composed of several layers of the flat epithelium. The tube wall was divided into four layers: mucosal, submucosal, muscular, and epithelial (serosal). Exception for the epidermal cells in the mucosal layer, the structures of the layers were similar to those of the intestinal tract. In the control group, the epithelial cells were arranged closely, and the muscle fibers in the muscle layer were observable clearly and arranged closely. The collagen fibers in the connective tissues of the submucosa and serosa were loose and wellorganized, and the central cavity was evident (Figure 1,1). After four days of $20 \% \mathrm{LC}_{50}$ semicarbazide treatment, the upper layer of the respiratory tree cavity became thinner and ruptured partially, the blood cavity thickened, and connective tissue thickened slightly. However, muscle fibers did not undergo significant changes (Figure 1,2). After 10 days of $4 \% \mathrm{LC}_{50}$ semicarbazide exposure, the blood cavity thickened, the endothelial cells became thinner, and the central cavity shrank (Figure 1,3). On day 28, there was still no apparent change in the muscle layer. However, the number of vacuoles between endothelial cells was increased, the epithelial layer was thickened, and cellular secretions were increased (Figure 1,4). No abnormal muscle fiber was observed on day 14 of $2 \% \mathrm{LC}_{50}$ semicarbazide treatment (Figure 1,5). Connective tissue was thickened slightly. The epithelial cell arrangement was disordered in the body cavity. The number of endothelial cells was increased, and vacuolation was apparent, albeit with no noticeable change in the central cavity (Figure 1,6).

Figure 1, 7-14 showed the damage sustained by the $A$. japonicus intestinal tract following exposure to semicarbazide. The intestinal wall was transparent relatively in the control group, and the four layers were distinct. The mucosal layer was a single layer of pseudostratified mucosal epithelium composed of columnar cells or cubic cells and mucus cells. The submucosa was composed of loose connective tissue. The muscular layer was divided into an inner longitudinal ring and an outer ring. The outer membrane was composed of flattened cells and their underlying thin layers of connective tissue. Exposure to 20\% $\mathrm{LC}_{50}$ semicarbazide thinned the connective tissues in the intestinal serosal layer, leading to partial disintegration on day 2 (Figure 1,7). No significant effect on the muscular layer fibers was observed. The connective tissue in the submucosa was thinner and vacuolated partially, with swollen mesothelial cells and folds slightly, which were still evident (Figure 1,8). On day 14, the serosal layer was thinner and disintegrated partially. Irregular striated margins and partial rupture were observed in muscle fibers, the connective tissue in the mucosal layer was thin, folds disappeared, and most cells were disintegrated (Figure 1,9). On day 28 , the intestinal structure was disintegrated utterly. In 
$4 \% \mathrm{LC}_{50}$ semicarbazide, the connective tissue in the serosal layer became thinner on day 6 , and the epithelial cells were swelled, but no disintegration was observed. The connective tissue in the mucosal layer became thinner, no folds were apparent, but no cellular disintegration was observed (Figure 1,10). On day 14, the connective tissue in the serosal layer thinned or disintegrated, and the muscular layer was disorganized. The connective tissue in the mucosal layer was thinner, and folds disappeared (Figure 1,11). When exposed to $2 \% \mathrm{LC}_{50}$ semicarbazide, the connective tissue in the submucosa became thinner on day 6 with some vacuolation (Figure 1,12). On day 7, the striated edge of the mucosal layer swelled, and the connective tissue in the submucosa was thinned, with twisted muscle fibers and partial rupture (Figure 1,13). On day 14, some epithelial cells were disintegrated, and the connective tissue in the submucosa appeared thinner, vacuolated, and transparent (Figure 1,14).

Figure 1, 15-22 showed the effects of semicarbazide on longitudinal muscle. In controls, the outermost epithelial cells were arranged evenly, with a relatively complete edge, and the smooth-muscle cells were arranged closely (Figure 1,15). Exposure to $20 \% \mathrm{LC}_{50}$ semicarbazide, coelomic epithelial cells were disrupted on day 5 , which resulted in ruptured plaques and distorted smooth muscle (Figure 1,16). On day 7, the epithelial layer of the body cavity was thickened, and the disruption to smooth muscle was exacerbated and evident (Figure 1,17). Longitudinal muscle tissues did not differ histologically between days 7 and 14 of exposure (Figure 1,18). The epithelial layer of the coelom remained thin until the end of the experiment (Figure 1,19). On day 5, the smooth muscle began to exhibit disruption exposed to $4 \% \mathrm{LC}_{50}$ semicarbazide (Figure 1,20). On day 7 , the smooth muscle was disrupted slightly in $2 \% \mathrm{LC}_{50}$ semicarbazide but did not differ between the other exposure groups and the controls (Figure 1,21). On day 14 , no other changes were observed, except for more severe disruption of smooth muscle (Figure 1,22).

Semicarbazide affected the tissue structure of the respiratory tree, intestinal tract, and longitudinal muscle. In the respiratory tree tissue, the high-exposure group lesions $\left(20 \% \mathrm{LC}_{50}\right.$ semicarbazide) were severe. Lesions developed more slowly exposed to $4 \% \mathrm{LC}_{50}$ semicarbazide, and the accumulation was gradual. In the intestinal tract, the connective tissue in the submucosa was thinned exposed to $20 \% \mathrm{LC}_{50}$ semicarbazide, and the cells in the longitudinal muscle layer were disordered. The intestinal tissue was disintegrated within 28 days. In the medium- and low-exposure groups, the connective tissue in the submucosa of the intestinal tract thinned slowly with the gradual accumulation of lesions. In longitudinal muscle tissue, exposure to $20 \% \mathrm{LC}_{50}$ semicarbazide caused lesions in smooth muscle, and the coelomic epithelial layer exhibited thickening and thinning in sequence. Coelomic cells in animals exposed to $4 \%$ or $2 \% \mathrm{LC}_{50}$ semicarbazide did not alter significantly, and the smooth-muscle lesions progressed slowly and gradually.

A. japonicus exposure to semicarbazide was manifested as loose or appearing pores of connective tissues in body wall, structural damage of water pipes in connective tissues, rupture or dissolution of epithelial layer in body cavity, and dissolution of viscera, etc. A. japonicus obtained strong autolytic ability extremely. The essence of autolysis was that A. japonicus was digested by the hydrolases, accompanied by the release of intracellular substances. After being stimulated by semicarbazide, the routine activities were disordered. The intestinal vomiting and body wall softening would occur. It was indicated that alkaline phosphatase was contained in the connective tissue layer of the body wall and the junction of the connective tissue layer and the muscle layer. And acid phosphatase was contained in the connective tissue fiber structure. The two enzymes were present in the tubular structure of the connective tissue layer mainly, which was in communication with the water pipe system of $A$. japonicus. The water pipe system was communicated with the outside environment through a stone pipe, and the tubular structure was in direct communication with the ocean. Autolysis of the body wall might be related to these two enzymes. Semicarbazide in the seawater stimulated the water tube tissue in the body wall through the water tube system, inducing the release of the two enzymes and acting on the connective tissue, which was closed to the water tube to generate the autolysis phenomenon of the body wall furtherly.

\section{Oxidative Stress}

Semicarbazide affected SOD activity in the respiratory tree, intestinal tract, and longitudinal muscle of A. japonicus at all exposure concentrations in Figure 2. Over time, SOD activity in each tissue increased firstly and then decreased, peaking within the first ten days of exposure. The highest activity was recorded in the medium-exposure group ( $4 \% \mathrm{LC}_{50}$ semicarbazide), followed by the high-exposure group and the low-exposure group. SOD activity differed from control levels in all three exposure groups, although the difference was smaller in the low-exposure group with a slight increase. SOD activity exposed to $4 \% \mathrm{LC}_{50}$ semicarbazide peaked at $1.785,1.674$, and 2.503 times the levels of the control group in the respiratory tree, intestinal tract, and longitudinal muscle, respectively. In general, SOD activity was higher in the respiratory tree and intestinal tract than longitudinal muscle and returned to control levels eventually.

In the group exposed to $2 \% \mathrm{LC}_{50}$ semicarbazide, $\mathrm{SOD}$ activity did not differ from control levels in the three tissues $(p>0.05)$, which suggested that the concentration was too low to affect enzymatic activity. However, the 28 days of exposure of semicarbazide at a low concentration could still induce $A$. japonicus to produce SOD, an antioxidant enzyme. In the group exposed to $4 \% \mathrm{LC}_{50}$ semicarbazide, the SOD activity was the highest in the respiratory tree, intestinal tract, and longitudinal muscle of $A$. japonicus. In the group exposed to $20 \% \mathrm{LC}_{50}$ semicarbazide, SOD activity was increased firstly, peaked on day 10 , and then decreased but did not return to control levels, and higher than the control group and $2 \% \mathrm{LC}_{50}$, lower than $4 \% \mathrm{LC}_{50}$ group. After the 21st day, A. japonicus showed a poisoning phenomenon in $20 \% \mathrm{LC}_{50}$ group, and some individuals died. It was inferred that semicarbazide was absorbed and produced toxic effects on A. japonicus after a certain accumulation period. 


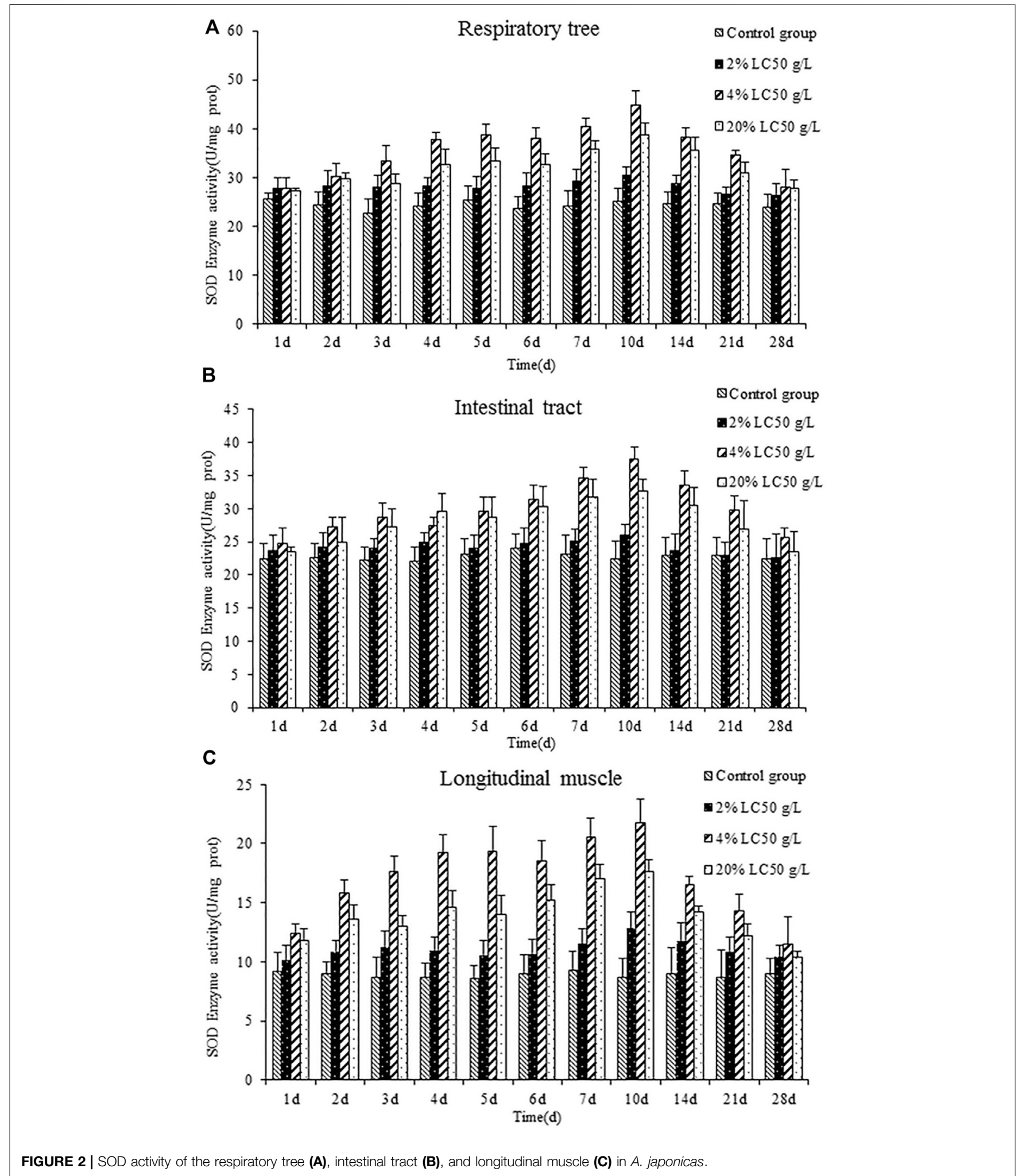

When in normal circumstances, the active oxygen substances were removed by antioxidants and antioxidant enzymes mainly. Under the stress of semicarbazide, the content of reactive oxygen species was increased. Meanwhile, SOD was increased, which played an essential role in the removal of reactive oxygen. However, the prolongation and intensity, even exceeding the capacity affected the synthesis of protein and other substances in cells, so the activity was decreased. 


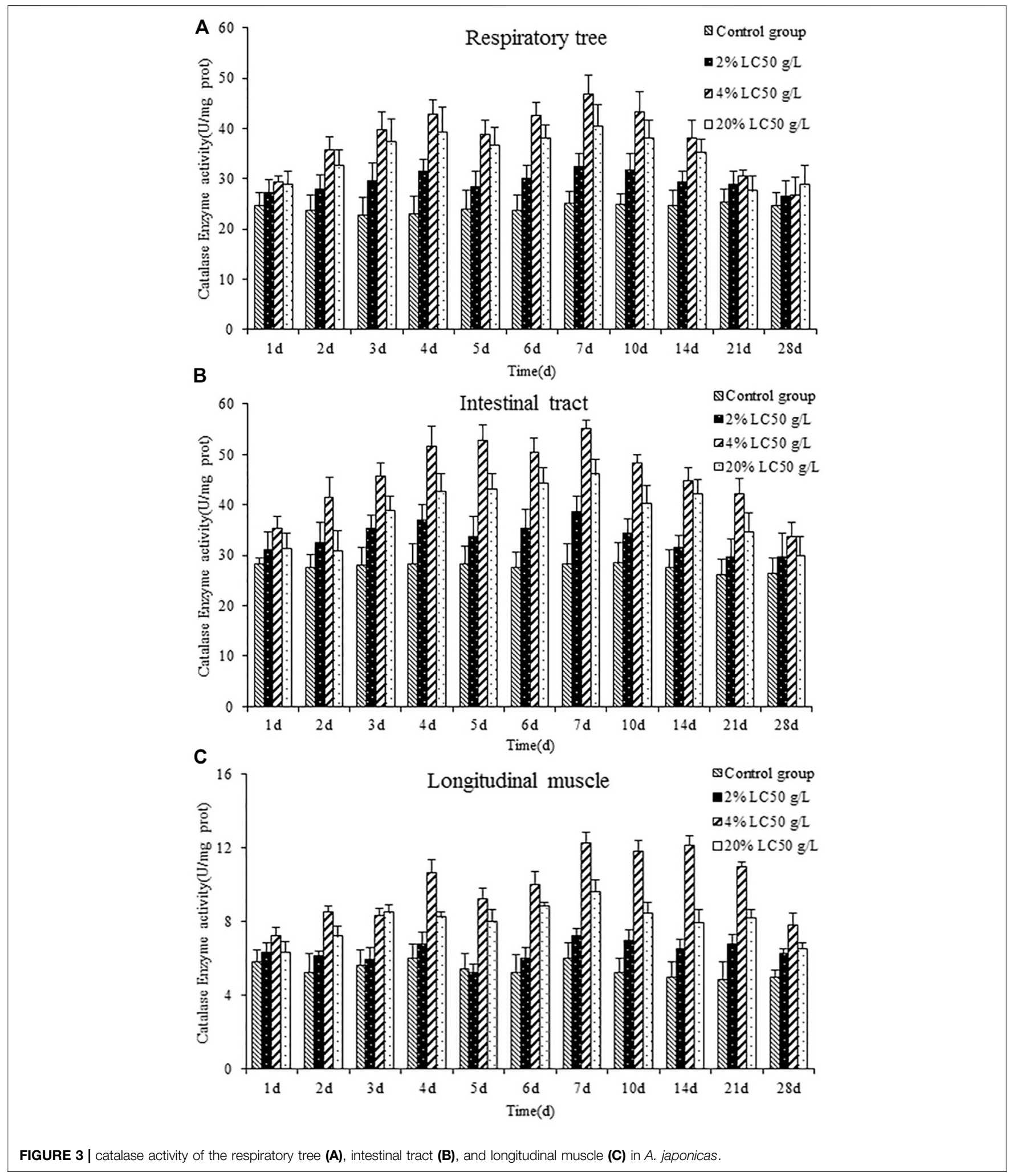

Figure 3 showed the effects of semicarbazide on catalase activity in the respiratory tree, intestinal tract, and longitudinal muscle of A. japonicus. Over time, catalase activity in each tissue was increased firstly and then decreased, peaking on day 7 .
Similar to SOD, catalase activity was highest in the $4 \% \mathrm{LC}_{50}$ group, followed by the high- and low-exposure groups. Maximum catalase activity in the respiratory tree, intestinal tract, and longitudinal muscle in the medium-exposure group 


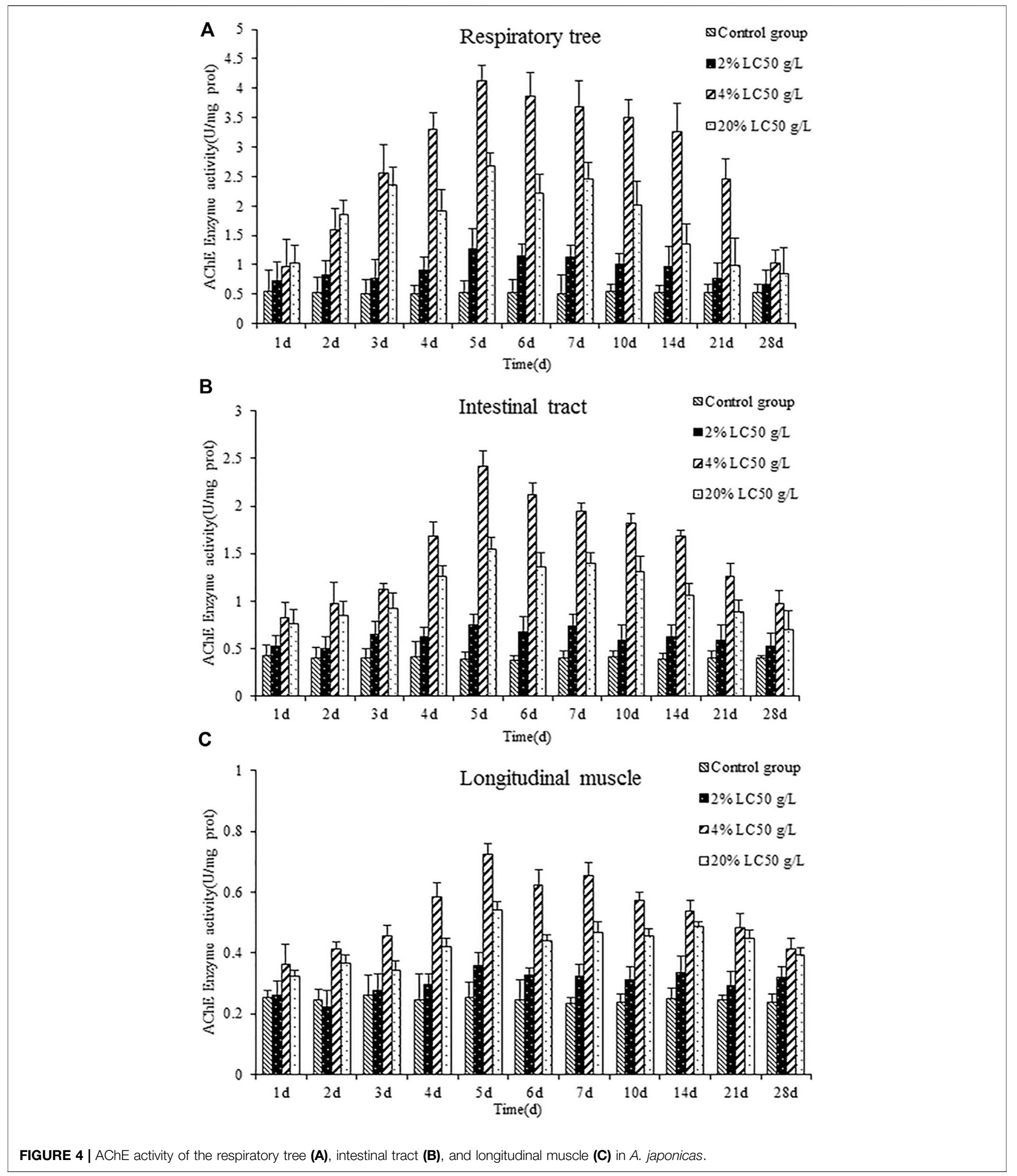

was $1.873,1.962$, and 2.036 times the activity in the control group, respectively. In general, catalase activity was highest in the intestinal tract, followed by the respiratory tree and longitudinal muscle, and returned to control levels eventually.
In the group exposed to $2 \% \mathrm{LC}_{50}$ semicarbazide, catalase activity did not differ from control levels in the three tissues $(p>0.05)$, which suggested that the concentration was too low to affect the activity. However, the long-term action of 
semicarbazide at low concentrations can still produce certain oxidative stress and induce $A$. japonicus to produce catalase, an antioxidant enzyme. In the group exposed to $4 \% \mathrm{LC}_{50}$ semicarbazide, the catalase activity was the highest in the respiratory tree, intestinal tract, and longitudinal muscle of $A$. japonicus. In the group exposed to $20 \% \mathrm{LC}_{50}$ semicarbazide, catalase activity was increased firstly, peaked on day 7 , and then decreased but did not return to the control levels, higher than the control group and $2 \% \mathrm{LC}_{50}$, lower than $4 \% \mathrm{LC}_{50}$ group. It was speculated that semicarbazide at $20 \% \mathrm{LC}_{50}$ may cause oxidative stress damage to A. japonicus. After the 21st day, A. japonicus in the $20 \% \mathrm{LC}_{50}$ group showed a poisoning phenomenon, and some individuals died, similar to SOD.

Also, under normal conditions, the active oxygen substances were removed by antioxidants and antioxidant enzymes mainly. Under the stress of semicarbazide, the content of reactive oxygen species was increased; meanwhile, catalase was increased, which played a critical response to the removal of reactive oxygen species. However, the prolongation and intensity, even exceeding the capacity affected the synthesis of protein and other substances in cells, so catalase activity was decreased.

\section{AChE Activity}

Figure 4 showed the effects of semicarbazide on AChE activity in the respiratory tree, intestinal tract, and longitudinal muscle of $A$. japonicus. Over time, AChE activity in each tissue was increased firstly and then decreased, peaking on day 5. Similar to SOD and catalase, AChE activity was highest in the medium-exposure group, followed by the high- and low-exposure groups. The increases were more significant in the high- and mediumexposure groups. Maximum $\mathrm{AChE}$ activity in the respiratory tree, intestinal tract, and longitudinal muscle in the mediumexposure group was $7.857,6.245$, and 2.862 times that of the control group, respectively. At each sampling point, AChE levels were higher generally in the respiratory tree, followed by the intestinal tract and longitudinal muscle, mirroring the findings for SOD but not catalase. Over time, AChE activity returned to control levels.

In the group exposed to $2 \% \mathrm{LC}_{50}$ semicarbazide, $\mathrm{AChE}$ activity did not differ from control levels in the three tissues, suggesting that the concentration was too low to affect the AChE activity. In the group exposed to $20 \% \mathrm{LC}_{50}$ semicarbazide, AChE activity was increased first, peaked on day 5 , and then decreased but did not return to control or low-exposure group levels $\left(2 \% \mathrm{LC}_{50}\right.$ semicarbazide). These findings suggested some damage to nerve conduction exerted by semicarbazide. Specifically, after 21 days, $A$. japonicus exposed to $4 \% \mathrm{LC}_{50}$ died, similar to SOD and catalase.

AChE, a crucial enzyme to ensure the normal transmission of biological nerve signals, was distributed in invertebrates and vertebrates widely. In this research, different concentrations of semicarbazide could stress on the acetylcholinesterase activity, exhibiting different performances at each treatment time. However, the overall trend was induction first and then inhibition. With the prolongation of exposure time, the induction was replaced by inhibition gradually, which would interfere with the degradation rate of acetylcholine inevitably, so that the interaction between acetylcholine and its receptor could not be terminated normally. Eventually some died in the high concentration group.

\section{Metabolomics Results}

Significantly different metabolites were selected by the importance of variables with projection scores (VIP) value greater than one and $p$ values less than 0.05 . The repeatability of quality control (QC) samples showed that the instrument was stable and the data were reliable. Differential metabolites were summarized between two groups and mapped onto biochemical pathways through metabolic enrichment and pathway analysis based on a database search (KEGG, http://www.genome.jp/kegg/). These metabolites were classified according to the pathways in which they were in or the functions performed. In this method, differences of metabolic spectra have reflected the biological differences between samples under exposure conditions or duration. 28 such metabolites were screened out in the positive ion mode, and, 38 were screened out in the negative ion mode, as shown in Table 3 and Table 4. KEGG pathway enrichment showed that the exposure affected pathways related to ABC transporters, central carbon metabolism in cancer, protein digestion and absorption, aminoacyl-tRNA biosynthesis, and biosynthesis of unsaturated fatty acids.

N1-acetylspermidine (M232T396), a significantly different metabolite in the dataset, was the spermidine acetylation product. In this research, the content of N1-acetylspermidine was up-regulated significantly, with the fold change 12.8. As a polyamine, spermidine was distributed in organisms widely and could inhibit neuronal nitric oxide synthase (Elik et al., 2020). Semicarbazide has been shown to antagonize N-methyl-D-aspartic acid (NMDAR) and affect its signal transduction pathway, which might lead to epilepsy and senile dementia eventually, as shown in Figure 5. Some impairment in the neural pathways was correlated with changes in AChE activity and the acetylcholine and dopamine levels of $A$. japonicus. In the nerve cells, acetylcholine (M146T305_2), a neurotransmitter, was synthesized by choline and acetyl coenzyme A under the catalysis of choline acetyltransferase. It was a significantly different metabolites in this research, up-regulated significantly with the fold change 1.43, which had been proved to improve the symptoms of Alzheimer's disease. Restoring dopamine levels in the brain has been thought to control Parkinson's disease and improve memory (Thompson and Tobin 2020). AChE can degrade the neurotransmitter acetylcholine rapidly, and terminate its exciting effect on acetylcholine receptor, thus maintaining the normal nerve conduction. AChE was a crucial enzyme in biological nerve conduction. Semicarbazide, heavy metals, pesticides, polycyclic aromatic hydrocarbons (PAHs), and other pollutants can cause abnormal changes in AChE activity in aquatic organisms (KopeckaPilarczyk., 2010; Kopecka-Pilarczyk and Correia., 2011; Shukor and Sulaman., 2013). Changes in AChE activity and the acetylcholine and dopamine levels in A. japonicus in metabolomics analysis indicated that the neural pathway was disturbed, needing further research for the mechanism. The results indicated that the neural pathway might be disturbed, corresponding to the change of $\mathrm{AChE}$ activity in A. japonicus (Qin 1996). 


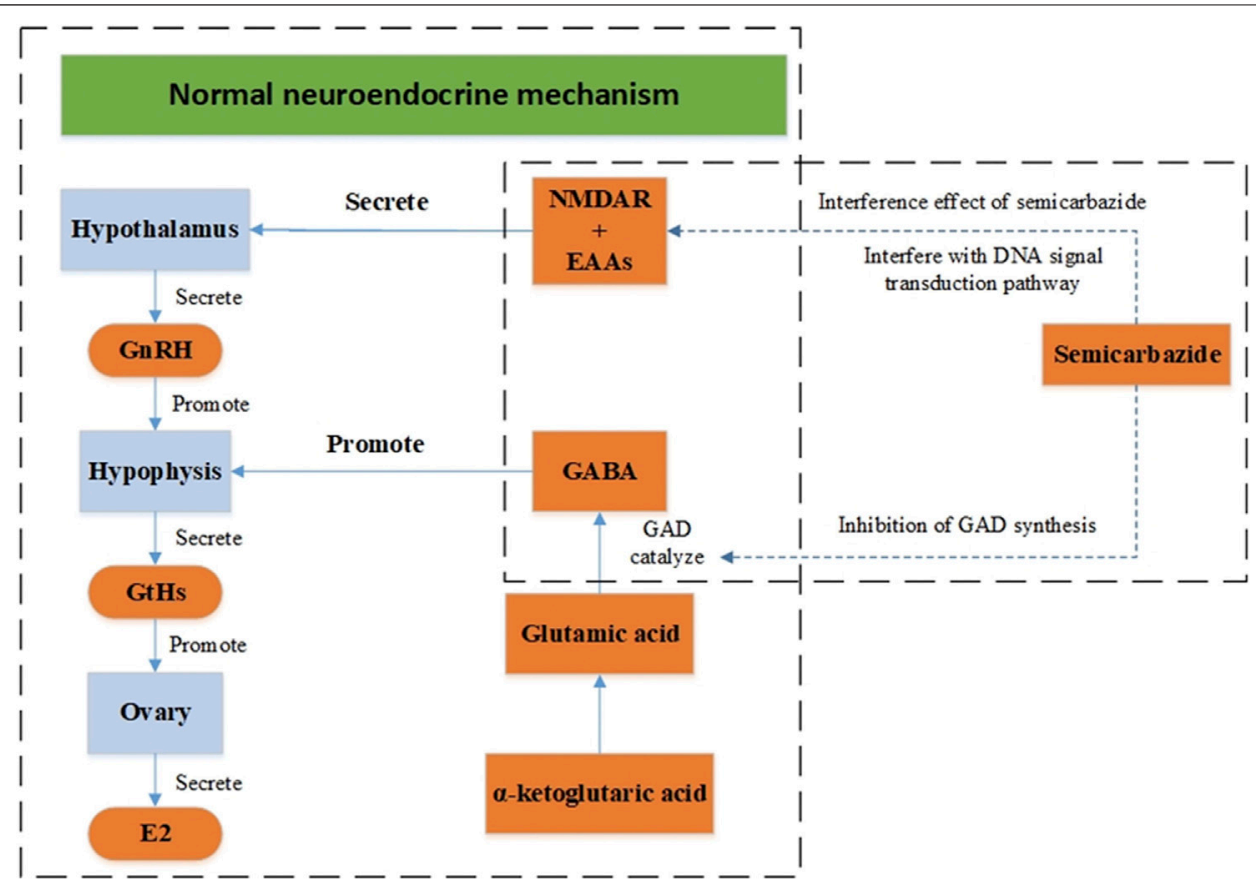

FIGURE 5 | Neuroendocrine regulation model of semicarbazide.

Functional pathway annotation of differential metabolites identified the predominant organic osmotic adjustment and energy metabolism related metabolites in exposed animals. Free amino acids were involved in osmotic pressure regulation in biological tissues. Exposure to semicarbazide modulated the levels of free taurine (M126T517_2, M124T517_2), succinic acid (M117T703_2), threonine (M118T649), leucine (M130T525), valine (M116T529), tyrosine (M182T530, M180T532), and aspartic acid (M132T738). Taurine (M126T517_2, M124T517_2) was distributed in the tissues and cells of marine animals widely. Succinic acid (M117T703_2) was an essential intermediate product in the energy metabolism pathway of invertebrates, and the final product of the anaerobic decomposition of glucose. It was found that an increase in succinic acid levels, which indicated the enhancement of anaerobic metabolism activity, which was related to impairments in energy metabolism probably. Similar findings have been reported in the tissues of the saltwater clam Ruditapes philippinarum exposed to heavy metals before (Liu et al., 2011a; Liu et al., 2011b).

It was also supported by two other significantly different metabolites, acetylcholine (M146T305_2) and dopamine (M136T531), with the fold change 1.43 and 1.87 . Acetylcholine was a neurotransmitter in the nerve cells, which was synthesized by choline and acetyl-CoA under the catalysis of choline acetyltransferase (choline acetyltransferase). Studies have shown that the increase of acetylcholine in the human body was significantly correlated with the improvement of Alzheimer's disease (senile dementia). Dopamine was a kind of neurotransmitter, also a chemical substance for cells to transmit pulses (Chambers et al., 2019). Arvid Carlsson, a scientist, believed that dopamine was the information transmitter in the brain, which won him the Nobel Prize in Medicine in 2000. In 2012, scientists discovered that dopamine could further help treat Parkinson's disease by restoring dopamine in the brain, and dopamine could improve memory, thus treating Alzheimer's disease (Kujacic and Carlsson 1995; Bloch 2000).

Two other significantly different metabolites were hypoxanthine nucleoside (M251T217) and hypoxanthine (M135T286). Hypoxanthine nucleoside was one of nucleoside compounds based on hypoxanthine, which was obtained from the reaction of adenosine with nitrous acid or enzymatic ammonolysis (Zhang et al., 2018). Hypoxanthine was produced under the action of nucleoside phosphate carboxylase. Hypoxanthine nucleoside could directly enter somatic cells directly through the cell membrane, and participate in nucleic acid metabolism, energy metabolism, and protein synthesis in vivo (Chiara and Claus-Peter., 2019). In addition, significant changes were observed in the digestion and absorption of protein, which indicated that energy metabolism and digestion and absorption of protein were affected in A. japonicus.

\section{CONCLUSION}

The acute and chronic effects of semicarbazide were assessed on respiratory tree, intestinal tract, and longitudinal muscle of the sea cucumber A. japonicus. The $96-\mathrm{h} \mathrm{LC}_{50}$ of semicarbazide 
hydrochloride was calculated. It was found that exposure to semicarbazide caused the changes in tissue morphology, oxidative stress, and AChE activity. Semicarbazide could cause the changes of the activity of SOD, catalase, and AChE, illustrating that semicarbazide could induce dysfunction of antioxidant defense system and nervous system. The differential metabolites and function mechanism were deduced by metabolomics to characterize toxicity and response mechanism in vivo exposed to semicarbazide.

Low levels and long-term exposures could also present adverse effects. However, there was a still lack of research on the potential impact of low concentration of semicarbazide on the ecological environment, which should be enough attention. Unlike fish and shellfish, sea cucumbers have not been the focus of research into the pollution of seawater aquaculture. This manuscript had offered a reference for further research into regulating environmental pollution that affected essential species economically to promote the healthy and sustainable development of $A$. japonicus crops. In the future, research on the toxicity of semicarbazone should be strengthened to clarify the accumulation effect of semicarbazone in aquatic animals and the toxicity and harm to high trophic level organisms in the ecological system.

\section{REFERENCES}

Abou-Setta, M. M., Sorrell, R. W., and Childers, C. C. (1986). A Computer Program in Basic for Determining Probit and Log-Probit or Logit Correlation for Toxicology and Biology. Bull. Environ. Contam. Toxicol. 36, 242-249. doi:10.1007/bf01623502

Authority, E. F. S. (2005). Panel on Food Additives Flavourings Processing Aids and Materials in Contact with Food. Opinion of the Scientific Panel on Food Additives, Flavourings, Processing Aids and Materials in Contact with Food on a Request from the Commission Related to Semicarbazide in Food. Parma. doi:10.2903/j.efsa.2005.242

Becalski, A., Lau, B. P.-Y., Lewis, D., and Seaman, S. (2006). Semicarbazide in Canadian Bakery Products. Food Additives and Contaminants 23, 107-109. doi:10.1080/02652030500395219

Becalski, A., Lau, B. P.-Y., Lewis, D., and Seaman, S. W. (2004). Semicarbazide Formation in Azodicarbonamide-Treated Flour: a Model Study. J. Agric. Food Chem. 52, 5730-5734. doi:10.1021/jf0495385

Bloch, B. (2000). Le Prix Nobel pour Arvid Carlsson ou la dopamine dans tous ses états. Med. Sci. (Paris) 16, 1285-1288. doi:10.4267/10608/1575

Chambers, N. E., Meadows, S. M., Taylor, A., Sheena, E., Lanza, K., Conti, M. M., et al. (2019). Effects of Muscarinic Acetylcholine M1 and M4 Receptor Blockade on Dyskinesia in the Hemi-Parkinsonian Rat. Neuroscience 409, 180-194. doi:10.1016/j.neuroscience.2019.04.008

Chiara, B., and Claus-Peter, W. (2019). AMP and GMP Catabolism in Arabidopsis Converge on Xanthosine, Which Is Degraded by a Nucleoside Hydrolase Heterocomplex. Plant Cell 31, 734-751. doi:10.1105/tpc.18.00899

Communities, E. (2003). Commission Decision vol No.2003/181 Brussels: EC.

Communities, E. (1993). EU Council Regulation vol No.2901/93 Brussels: EC.

Communities, E. (1995). EU Council Regulation vol No. 1442/95 Brussels: EC.

Dong, D. S. (2007). Temperature Effects on Growth-Ration Relationships of Juvenile Sea Cucumber Apostichopus Japonicus (Selenka). Aquaculture 272, 664-648. doi:10.1016/j.aquaculture.2007.08.038

EFSA (2003a). Additional Advice on Semicarbazide Particular Related to Baby Food. Parma.

EFSA (2003b). Advice of the Ad Hoc Expert Group Set up to Advise the European Food Safety Authority (EFSA) on the Possible Occurrence of Semicarbazide in Packaged Foods. Parma.

\section{DATA AVAILABILITY STATEMENT}

The original contributions presented in the study are included in the article/Supplementary Material, further inquiries can be directed to the corresponding authors.

\section{AUTHOR CONTRIBUTIONS}

All authors contributed to the study conception and design. Material preparation, data collection and analysis were performed by XT, HL, XZ, YX, HZ, DH, HL, BW, YC, HL, QZ and XG. The first draft of the manuscript was written by XT and all authors commented on previous versions of the manuscript. All authors read and approved the final manuscript.

\section{FUNDING}

The work was supported by the National Key R\&D Program of China (grant no. 2017YFC1600702), Key lab of marine bioactive substance and modern analytical technique, SOA (grant no. MBSMAT-2019-04), the Modern Agro-industry Technology Research System in Shandong Province (grant no. SDAIT-26-05).

EFSA (2003c). Statement of the Scientific Panel on Food Additives, Flavourings, Processing Aids and Materials in Contact with Food Updating the Advice Available on Semicarbazide in Packaged Foods. Parma.

Elik, H., Küükler, S., Comakli, S., Zdemir, S., and Kandemir, F. M. (2020). Morin Attenuates Ifosfamide-Induced Neurotoxicity in Rats via Suppression of Oxidative Stress, Neuroinflammation and Neuronal Apoptosis. NeuroToxicology 76, 126-137. doi:10.1016/j.neuro.2019.11.004

Finney, D. J. (1972). In Probit Analysis. J. R. Stat. Soc. 21, 25-35. doi:10.2307/ 2986688

Fleming, L. E., Broad, K., Clement, A., Dewailly, E., Elmir, S., Knap, A., et al. (2006). Oceans and Human Health: Emerging Public Health Risks in the marine Environment. Mar. Pollut. Bull. 53, 545-560. doi:10.1016/ j.marpolbul.2006.08.012

Gao, S., Wang, W., Tian, H., Zhang, X., Guo, L., and Ru, S. (2014). An Emerging Water Contaminant, Semicarbazide, Exerts an Anti-estrogenic Effect in Zebrafish (Danio rerio). Bull. Environ. Contam. Toxicol. 93, 280-288. doi:10.1007/s00128-014-1305-7

Hirakawa, K., Midorikawa, K., Oikawa, S., and Kawanishi, S. (2003). Carcinogenic Semicarbazide Induces Sequence-specific DNA Damage through the Generation of Reactive Oxygen Species and the Derived Organic Radicals. Mutat. Research/Genetic Toxicol. Environ. Mutagenesis 536, 91-101. doi:10.1016/s1383-5718(03)00030-5

Kopecka-Pilarczyk, J., and Correia, A. D. (2011). Effects of Exposure to PAHs on Brain AChE in Gilthead Seabream, Sparus aurata L., under Laboratory Conditions. Bull. Environ. Contam. Toxicol. 86, 379-383. doi:10.1007/ s00128-011-0234-y

Kopecka-Pilarczyk, J. (2010). The Effect of Pesticides and Metals on Acetylcholinesterase (AChE) in Various Tissues of Blue Mussel (Mytilus trossulusL.) in Short-Termin Vivoexposures at Different Temperatures. J. Environ. Sci. Health B 45, 336-346. doi:10.1080/ 03601231003704390

Kujacic, M., and Carlsson, A. (1995). In Vivo activity of Tyrosine Hydroxylase in Rat Adrenal Glands Following Administration of Quinpirole and Dopamine. Eur. J. Pharmacol. 278, 9-15. doi:10.1016/0014-2999(95) 00092-y

Liu, X., Xue, C., Wang, Y., Li, Z., Xue, Y., and Xu, J. (2012). The Classification of Sea Cucumber (Apostichopus Japonicus) According to Region of Origin Using 
Multi-Element Analysis and Pattern Recognition Techniques. Food Control 23, 522-527. doi:10.1016/j.foodcont.2011.08.025

Liu, X., Zhang, L., You, L., Cong, M., Zhao, J., Wu, H., et al. (2011a). Toxicological Responses to Acute Mercury Exposure for Three Species of Manila Clam Ruditapes Philippinarum by NMR-Based Metabolomics. Environ. Toxicol. Pharmacol. 31, 323-332. doi:10.1016/j.etap.2010.12.003

Liu, X., Zhang, L., You, L., Yu, J., Zhao, J., Li, L., et al. (2011b). Differential Toxicological Effects Induced by Mercury in Gills from Three Pedigrees of Manila Clam Ruditapes Philippinarum by NMR-Based Metabolomics. Ecotoxicology 20, 177-186. doi:10.1007/s10646-010-0569-x

Nardelli, M., Fava, G., and Giraldi, G. (1965). The Crystal and Molecular Structure of Semicarbazide Hydrochloride. Acta Crystallogr. 19, 1038-1042. doi:10.1107/ S0365110X65004851

Partelow, S., von Wehrden, H., and Horn, O. (2015). Pollution Exposure on marine Protected Areas: A Global Assessment. Mar. Pollut. Bull. 100, 352-358. doi:10.1016/j.marpolbul.2015.08.026

Qin, Z. (1996). Stimulation of N-Methyl-?-Aspartate Receptors Induces Apoptosis in Rat Brain. Brain Res. 725, 166-176. doi:10.1016/s0006-8993(96)00200-4

Raja, R., Seshadri, S., Santhanam, V., and Vedhavalli, D. (2017). Growth and Characterization of Nonlinear Optical crystal - Semicarbazide Picrate. J. Mol. Struct. 1147, 515-519. doi:10.1016/j.molstruc.2017.06.035

Rajeshkumar, S., Liu, Y., Ma, J., Duan, H. Y., and Li, X. (2017). Effects of Exposure to Multiple Heavy Metals on Biochemical and Histopathological Alterations in Common Carp, cyprinus Carpio L. Fish Shellfish Immunol. 70, 461-472. doi:10.1016/j.fsi.2017.08.013

Register, F. (2002). Topical Nitrofurans; Extralabel Animal Drug Use; Order of Prohibition. Washington: Food and Drug Administration, HHS. doi:10.21236/ ada417286

Santos, J. M., Macedo, C. E., and Brandão, M. L. (2008). Gabaergic Mechanisms of Hypothalamic Nuclei in the Expression of Conditioned Fear. Neurobiol. Learn. Mem. 90 (3), 560-568. doi:10.1016/j.nlm.2008.06.007

Shukor, M. S., and Sulaiman, M. R. (2013). Assessment of Acetylcholinesterase (Ache) from Silver Catfish (Pangasius sp.) as an Assay for Organophosphates and Carbamates. Biosci. Biotechnol. Res. Asia 10, 213-218. doi:10.13005/bbra/1112

Takahashi, M., Yoshida, M., Inoue, K., Morikawa, T., Nishikawa, A., and Ogawa, K. (2014). Chronic Toxicity and Carcinogenicity of Semicarbazide Hydrochloride in Wistar Hannover GALAS Rats. Food Chem. Toxicol. 73, 84-94. doi:10.1016/ j.fct.2014.08.006

Tarek, M., Zaki, M., Fawzy, M. H., and Assey, M. M. (1986). Application of Rhodanine, Fluorene and Semicarbazide Hydrochloride as New Spectrophotometric Reagents for Quinones. Mikrochim Acta 90, 321-328. doi:10.1007/bf01199274

Thompson, K. J., and Tobin, A. B. (2020). Crosstalk between the M1 Muscarinic Acetylcholine Receptor and the Endocannabinoid System: A Relevance for Alzheimer's Disease? 70. Elsevier Sponsored Documents. doi:10.1016/ j.cellsig.2020.109545

Tian, X., Xu, Y., Gong, X., Han, D., Wang, Z., Zhou, Q., et al. (2017). Environmental Status and Early Warning Value of the Pollutant
Semicarbazide in Jincheng and Sishili Bays, Shandong Peninsula, China. Sci. Total Environ. 576, 868-878. doi:10.1016/j.scitotenv.2016.10.085

Tian, X., Xu, Y., Song, X., Gong, X., Liu, Y., Zhou, Q., et al. (2016). Temporal and Spatial Distribution of Semicarbazide in Western Laizhou Bay. Mar. Pollut. Bull. 112, 393-398. doi:10.1016/j.marpolbul.2016.07.052

Wang, Y., Chan, H. W., and Chan, W. (2016). Facile Formation of a DNA Adduct of Semicarbazide on Reaction with Apurinic/Apyrimidinic Sites in DNA. Chem. Res. Toxicol. 29, 834-840. doi:10.1021/acs.chemrestox.6b00011

Xia, S., Yang, H., Li, Y., Liu, S., Zhou, Y., and Zhang, L. (2012). Effects of Different Seaweed Diets on Growth, Digestibility, and Ammonia-Nitrogen Production of the Sea Cucumber Apostichopus Japonicus (Selenka). Aquaculture 338-341, 304-308. doi:10.1016/j.aquaculture.2012.01.010

Yu, M., Feng, Y., Zhang, X., Wang, J., Tian, H., Wang, W., et al. (2017). Semicarbazide Disturbs the Reproductive System of Male Zebrafish (Danio rerio) through the GABAergic System. Reprod. Toxicol. 73, 149-157. doi:10.1016/j.reprotox.2017.08.007

Yu, M., Zhang, X., Guo, L., Tian, H., Wang, W., and Ru, S. (2016). Anti-estrogenic Effect of Semicarbazide in Female Zebrafish (Danio rerio) and its Potential Mechanisms. Aquat. Toxicol. 170, 262-270. doi:10.1016/j.aquatox.2015.11.025

Zhang, M., Jia, S., Liu, Y., Liu, Y., Li, S., Bo, L., et al. (2018). Metabonomics Analysis of Kidneys in Rats Administered with Chronic Low-Dose Cadmium by Ultraperformance Liquid Chromatography-Mass Spectrometry. J. Appl. Toxicol. 39, 441-450. doi:10.1002/jat.3735

Zhao, H., Guo, W., Quan, W., Jiang, J., and Qu, B. (2016). Occurrence and Levels of Nitrofuran Metabolites in Sea Cucumber from Dalian, China. Food Additives \& Contaminants: A 33, 1672-1677. doi:10.1080/19440049.2016.1217069

Zhao, X., Gao, Y., and Qi, M. (2014). Toxicity of Phthalate Esters Exposure to Carp (cyprinus Carpio) and Antioxidant Response by Biomarker. Ecotoxicology 23, 626-632. doi:10.1007/s10646-014-1194-x

Conflict of Interest: The authors declare that the research was conducted in the absence of any commercial or financial relationships that could be construed as a potential conflict of interest.

Publisher's Note: All claims expressed in this article are solely those of the authors and do not necessarily represent those of their affiliated organizations, or those of the publisher, the editors and the reviewers. Any product that may be evaluated in this article, or claim that may be made by its manufacturer, is not guaranteed or endorsed by the publisher.

Copyright $\odot 2021$ Tian, Li, Zhang, Xu, Zhang, Han, Liu, Wang, Cui, Liu, Zhou and Gong. This is an open-access article distributed under the terms of the Creative Commons Attribution License (CC BY). The use, distribution or reproduction in other forums is permitted, provided the original author(s) and the copyright owner(s) are credited and that the original publication in this journal is cited, in accordance with accepted academic practice. No use, distribution or reproduction is permitted which does not comply with these terms. 